\title{
Theoretical and Experimental Investigation of the Formation of $E$ - and Z-Aldimines from the Reaction of Methylamine with
}

\section{Acetaldehyde}

\author{
Josefredo R. Pliego Jr. ${ }^{\mathrm{a} \mathrm{b}_{*}, \text { Antônio Flávio de C. Alcântara }}{ }^{\mathrm{c}}$, \\ Dorila Piló Veloso $^{\mathrm{b}_{*}}$, and Wagner B. de Almeida ${ }^{\mathrm{a}, \mathrm{b}_{*}}$ \\ ${ }^{\mathrm{a}}$ Laboratório de Química Computacional e Modelagem Molecular (LQC-MM) \\ ${ }^{\mathrm{b}}$ Depto de Química, ICEx, Universidade Federal de Minas Gerais, \\ 31270-901 Belo Horizonte - MG, Brazil \\ ${ }^{\mathrm{c}}$ Depto de Química, ICE, Universidade do Amazonas, 69078-000 Manaus - AM, Brazil \\ A reação entre metilamina e acetaldeído em pentano a $230 \mathrm{~K}$ leva à formação das aldiminas $E$ - \\ e $Z$-, sendo o isômero $Z$ - o produto principal e gerado sob controle cinético. O isômero $E$ - é mais \\ estável do que o $Z$ - por $3.3 \mathrm{kcal} / \mathrm{mol}\left(\Delta \mathrm{G}^{*}\right)$. Os cálculos ab initio mostraram que a etapa bimolecular \\ de adição ocorre por um processo concertado, com formação da ligação $\mathrm{C}-\mathrm{N}$ e transferência de \\ próton através de um estado de transição de quatro centros. O intermediário zwiteriônico, frequen- \\ temente invocado neste tipo de reação, não existe como um mínimo na superfície de energia \\ potencial. Entretanto, a energia livre de ativação para o mecanismo concertado é muito alta, e não \\ é capaz de explicar a cinética deste processo. O mesmo acorre com a etapa de eliminação de água \\ para formar a imina, ou seja, possui uma barreira de ativação muito alta. Estes resultados implicam \\ que tanto a etapa de adição, como a de eliminação, devem ocorrer por um mecanismo de catálise. \\ $O$ isômero $Z$ - pode se interconverter para a forma $E$ - através de uma inversão sobre o nitrogênio \\ $\mathrm{sp}^{2}$. A $298.15 \mathrm{~K}$, a energia livre de ativação para este processo foi calculada como sendo 27.0 \\ $\mathrm{kcal} / \mathrm{mol}$, o que leva a um tempo de vida de quatro meses para este isômero. \\ The reaction of methylamine with acetaldehyde in pentane at $230 \mathrm{~K}$ leads to formation of both \\ $E$ - and $Z$ - aldimines, the $Z$-isomer being the main product and generated upon kinetic control. The \\ $E$-form is more stable than the $Z$ - form by $3.3 \mathrm{kcal} / \mathrm{mol}\left(\Delta \mathrm{G}^{*}\right)$. Ab initio calculations have indicated \\ that a tetrahedral zwitterion intermediate is not formed, and the bimolecular process, forming the \\ aminoalcohol intermediate, occurs through a four center transition state, with concerted formation \\ of C-N bond and proton transfer. However, the predicted $\Delta \mathrm{G}^{* \neq}$ is very high, indicating that the true \\ mechanism for this step is not bimolecular. A catalyzed pathway must be actuating. The following \\ step, unimolecular elimination of water, also presents a very high activation free energy. Similarly, \\ a catalyzed mechanism is needed. The isomerization from the $Z$ - form to the $E$ - form through \\ inversion of the nitrogen atom has a predicted $\Delta \mathrm{G}^{* \neq}$ of $27.0 \mathrm{kcal} / \mathrm{mol}$ at $298.15 \mathrm{~K}$, resulting in a \\ lifetime of four months for the $Z$-isomer.
}

Keywords: reaction mechanism, E- and Z-Aldimines equilibrium, ab initio calculations

\section{Introduction}

The study of the properties and the formation of imines has great interest due to its role in several important chemical processes ${ }^{1}$, mainly in the synthesis of polyazocycles ${ }^{2}$ and other nitrogened heterocycle compounds ${ }^{3}$. In relation to its biological importance ${ }^{1}$, the literature reports the par- ticipation of the imine group in the synthesis of artificial oxiredutases ${ }^{4}$, in the formation of compounds with antivi$\mathrm{ral}^{5}$, antimicrobial ${ }^{6}$, antihypertensive ${ }^{7}$, and antitumor ${ }^{8}$ activities, and also in the synthesis of penicilin ${ }^{9}$, cefaloporfirin $^{10}$ and nocardicin ${ }^{11}$, and many other biologically active compounds ${ }^{12}$. 
Although they have a large applicability, methodological studies have been addressed mainly to obtain aromatic aldimines and ketimines, as they are relatively stable under several experimental conditions ${ }^{13}$. On the other hand, aliphatic aldimines have been less chemically studied due to their instability in protic solvents and acidic medium ${ }^{14}$. In these situations, they can undergo imine-enamine tautomeric equilibrium $^{15}$ and imine-imine isomerization ${ }^{16}$, leading to the formation of several auto-condensation products $^{17}$, and decreasing their yield ${ }^{18}$. Thus, experimental procedures for the preparation of aliphatic aldimines have become more specific in order to improve the yield ${ }^{19}$.

The reaction mechanism of amine addition to carbonyl compounds in aqueous solution has been studied at the experimental level ${ }^{20-24}$, and some theoretical studies have been reported ${ }^{25,26}$. Sayer et al has proposed a general mechanism for this reaction in aqueous solution and at variable $\mathrm{pH}$. The first step can be catalyzed by $\mathrm{H}_{3} \mathrm{O}^{+}$at low $\mathrm{pH}$, forming the aminoalcohol intermediate. Increasing the $\mathrm{pH}$, a competitive uncatalyzed mechanism can take place, which occurs through the formation of a supposed zwitterion tetrahedral intermediate. This species could dissociate backward, or rearrange to aminoalcohol in an acid catalyzed or uncatalyzed mechanism. Support for this mechanism was provided by the $\mathrm{pH}$ dependent rate profile. However, ab initio studies by Yamataka et $a l^{25}$ for the addition of several amines to carbonyls do not support this proposed mechanism. The zwitterion intermediate is not a minimum energy structure on the potential energy surface, and these authors have found a four-center transition state for this step, generating directly the aminoalcohol. Another ab initio study of the $\mathrm{NH}_{3}$ addition to $\mathrm{HCHO}$ carried out by Williams ${ }^{26}$ has shown that one or two water molecules can act as a catalyst through a cyclic transition state. These results raise doubts about the formation of the zwitterion intermediate, and point out that the uncatalyzed mechanism in reality is water catalyzed.

The second step of the reaction is the water elimination of the aminoalcohol, forming the imine. This step can be acid catalyzed in low $\mathrm{pH}$, and presents a competitive uncatalyzed mechanism, which can become important when the $\mathrm{pH}$ increases. So, in the case of a reaction involving amine and aldehyde in a neutral and low polarity medium, which is the interest of this study, the overall mechanism can be represented by the Scheme 1, where we have included the possibility of the formation of both $E$ - and $Z$ isomers.
The interconversion from $E$ - to $Z$-isomers of imines has been the object of many theoretical and experimental studies which have addressed questions on the mechanism, kinetics and thermodynamics of this process ${ }^{16,27-34}$. These studies pointed out that in aprotic medium, isomerization occurs by inversion of the nitrogen atom, as indicated in Scheme 2. For the prototypical methylimine species, $a b$ initio calculations by Pople et $a l^{29}$ indicated a barrier of 30.5 $\mathrm{kcal} / \mathrm{mol}$ at $\mathrm{MP} 4 / 6-31 \mathrm{G}^{* *} / / \mathrm{HF} / 6-31 \mathrm{G}^{*}$ level of theory. With the increase of the groups bonded to nitrogen and carbon, this barrier can decrease by up to $15 \mathrm{kcal} / \mathrm{mol}$, as found in experimental studies ${ }^{34}$. In thermodynamic terms, either $E$ - or $Z$-isomers can be the more stable, depending on the substituinte groups. For aldimines, $E$-isomers in general present lower free energy. As an example, Wiberg ${ }^{31}$ has combined experimental and theoretical data to obtain the heat of formation of $(E)$ - and $(Z)-\mathrm{N}$-methyl-acetaldimine, and has found that the $E$ - isomer is more stable by 4.4 $\mathrm{kcal} / \mathrm{mol}$. Another pathway to isomerization is by enamine formation in protic medium ${ }^{27,30}$. For acetaldimine, the enamine form is less stable by $3.94 \mathrm{kcal} / \mathrm{mol}^{32}$, and depending on the substituinte groups, this order can be reversed ${ }^{33}$. The catalysis by the solvent in this pathway is evident, since a unimolecular process involves a high activation energy, $66.34 \mathrm{kcal} / \mathrm{mol}$ for acetaldimine $\mathrm{e}^{33}$.<smiles>[R]C([R])=O</smiles><smiles>[R]N</smiles><smiles>[R2]NC([R])O</smiles>

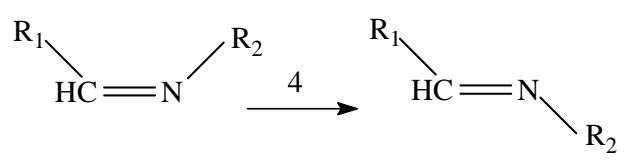

$$
Z \text { - isomer } \quad E \text { - isomer }
$$

Scheme 1.

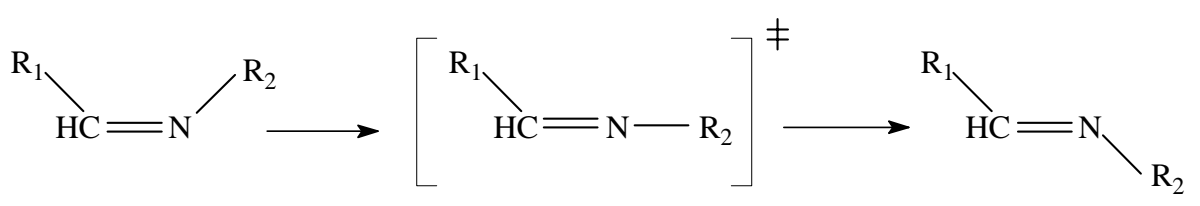

Scheme 2. 
In order to obtain stereochemical control in aldimine synthesis, the above discussion should be taken into consideration before proceeding with the experiment. In the present work, our aim is to study the mechanism, kinetic and thermodynamics for the formation of a prototypical aldimine, N-methyl-acetaldimine. We hope that this study might help in the planning of the synthesis of aldimines with a specific isomeric form.

\section{Experimental}

The ${ }^{1} \mathrm{H}-\mathrm{NMR}$ spectra were recorded on a Bruker DRX 400 using pentane and $\mathrm{CDCl}_{3}$ as solvents and TMS as the internal reference. The spectrum was registered with signal suppression of trace of $\mathrm{CHCl}_{3}$, using a temperature variable program.

The reaction was conducted utilizing the following procedure: Methylamine 0.1 mol (Note: aqueous solution of methylamine $25 \% \mathrm{p} / \mathrm{v}$ was utilized), $100 \mathrm{~mL}$ of pentane and $65 \mathrm{~g}$ of anhydrous sodium sulfate in a 3-necked, roundbottomed flask connected to an addition funnel and a condenser with a drying tube. After the mixture has been stirred for $1 \mathrm{~h}$ at $0{ }^{\circ} \mathrm{C}$, acetaldehyde $0.1 \mathrm{~mol}$ (purified by bidistillation at atmospheric pressure) was slowly added with vigorous stirring at $200 \mathrm{~K}$. Aliquots of the reaction mixture were analyzed by ${ }^{1} \mathrm{H}-\mathrm{NMR}$ at temperatures of $230 \mathrm{~K}$.

The ratio of aldehyde to imine in the reaction mixtures was calculated by the integration of the signals corresponding to the aldehydic hydrogen near to $\delta 9.0$ and the aldiminic hydrogens near to $\delta 7.0$. An error of $2.5 \%$ in the ratio of the integrals of signals was estimated using standard solutions of butanal and chloroform.

\section{Ab Initio Calculations}

The potential energy surface for methylamine addition to acetaldehyde was investigated at the $a b$ initio HartreeFock (HF) and second order M $\phi$ ller-Plesset Perturbation Theory (MP2) levels, using the $6-31 \mathrm{G}^{*}, 6-31+\mathrm{G}^{*}$ and $6-311+\mathrm{G}(2 \mathrm{~d}, \mathrm{p})$ basis sets. Full geometry optimizations and harmonic frequency calculations were performed at the $\mathrm{HF} / 6-31 \mathrm{G}^{*}$ level, and in order to obtain a good estimate of reaction and activation energies, single point calculations were carried out at the MP2 level using the $6-31+\mathrm{G}^{*}$ and $6-311+\mathrm{G}(2 \mathrm{~d}, \mathrm{p})$ basis sets. The ab initio data were used to determine the thermodynamic and kinetic parameters for each step by statistical mechanics and transition state theory calculations ${ }^{35-37}$. The harmonic frequencies scaled by a factor of 0.90 were used in the calculation of the vibrational partition function. The symbols ${ }^{\circ}$ and $*$ were used to represent the standard states of $1 \mathrm{~atm}$ of pressure and $1 \mathrm{~mol} / \mathrm{L}$ of concentration (free energy). The parameters $\mathrm{H}^{*}$ and $\mathrm{S}^{*}$ are defined by the relations:

$$
S^{*}=-\frac{\partial G^{*}}{\partial T} \quad H^{*}=G^{*}+T^{*}
$$

The optimized structures are in Fig. 1 and the results of the calculations in Tables 1 and 2. All ab initio calculations were performed using the GAUSSIAN 94 program $^{38}$.

\section{Results}

The ${ }^{1} \mathrm{H}-\mathrm{NMR}$ spectrum of an aliquot of the reaction mixture between methylamine and acetaldehyde after 1 hour at $230 \mathrm{~K}$ presents a quartet signal in $\delta 9.75$, attributed to aldehydic hydrogen. The singlet signals at $\delta 7.31$ and $\delta$ 7.19 are attributed to aldiminic hydrogens of the two isomers. Analyzing the integration of signals (proportion of $11.86,1.00$ and 1.74 , respectively) we can note that in the time of the experimental measurements, just $19 \%$ of the aldehyde has reacted (not considering the aminoalcohol), forming both $E$ - and $Z$-isomers. We have attributed the $\delta$

Table 1. Reaction energies and thermodynamics properties for methylamine addition to acetaldheyde determined by ab initio calculations ${ }^{\mathrm{a}}$.

\begin{tabular}{|c|c|c|c|c|}
\hline & 1 & 2 & 3 & 4 \\
\hline \multicolumn{5}{|c|}{$6-31 G(d)$} \\
\hline $\mathrm{HF}$ & -7.0 & 17.0 & 12.8 & -4.2 \\
\hline$\Delta \mathrm{ZPE}^{\mathrm{b}}$ & 3.8 & -5.0 & -5.0 & 0.0 \\
\hline \multicolumn{5}{|c|}{$6-31+G(d)$} \\
\hline $\mathrm{HF}$ & -6.1 & 15.1 & 10.7 & -4.4 \\
\hline MP2 & -12.9 & 16.4 & 12.0 & -4.4 \\
\hline \multicolumn{5}{|c|}{$6-311+G(2 d, p)$} \\
\hline MP2 & -13.6 & 14.1 & 10.0 & -4.1 \\
\hline$\Delta \mathrm{E}^{\mathrm{c}}$ & -9.8 & 9.1 & 5.0 & -4.1 \\
\hline \multicolumn{5}{|c|}{ Thermodynamics properties ${ }^{\mathrm{d}}$} \\
\hline$\Delta \mathrm{H}^{\mathrm{o}}$ & -10.9 & 10.9 & 6.6 & -4.3 \\
\hline$-\mathrm{T} \Delta \mathrm{S}^{\mathrm{O}}$ & 12.2 & -12.3 & -11.3 & 1.0 \\
\hline$\Delta \mathrm{G}^{\mathrm{o}}$ & 1.3 & -1.4 & -4.7 & -3.3 \\
\hline$\Delta \mathrm{H}^{*}$ & -10.3 & 10.3 & 6.0 & -4.3 \\
\hline$-\mathrm{T} \Delta \mathrm{S}^{*}$ & 9.7 & -9.8 & -8.8 & 1.0 \\
\hline$\Delta \mathrm{G}^{*}$ & -0.6 & 0.5 & -2.8 & -3.3 \\
\hline \multicolumn{5}{|c|}{ Equilibrium constants } \\
\hline $\mathrm{K}_{\mathrm{eq}}^{\mathrm{e}}$ & 2.8 & 0.4 & $1.1 \times 10^{2}$ & $2.6 \times 10^{2}$ \\
\hline \multicolumn{5}{|c|}{$\begin{array}{l}\text { a - Each step is numbered according to Scheme } 1 \text {. Energies are in } \mathrm{kcal} / \mathrm{mol} \text {, } \\
\text { and the symbols }{ }^{\circ} \text { and } * \text { correspond to standard state of } 1 \mathrm{~atm} \text { of pressure } \\
\text { and } 1 \mathrm{~mol} / \mathrm{L} \text { of concentration. } \mathrm{T}=298.15 \mathrm{~K} \text {. } \\
\mathrm{b} \text { - Zero point vibrational energy contribution. Frequencies scaled by } 0.90 \text {. } \\
\mathrm{c} \text { - MP2/6-311+G(2d, p) energy }+\Delta \mathrm{ZPE} \text {. } \\
\mathrm{d} \text { - The two enantiomers of the aminoalcohol were considered in the } \\
\text { calculation of the thermodynamics properties. } \\
\text { e - Equilibrium constant at } 298.15 \mathrm{~K} \text {. Units of mol and L. }\end{array}$} \\
\hline
\end{tabular}




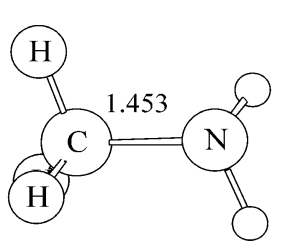

MS1a

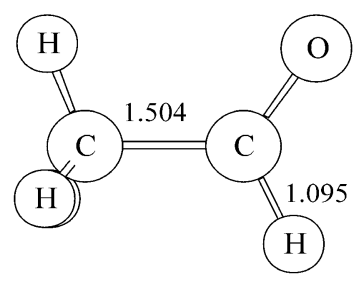

MS1b

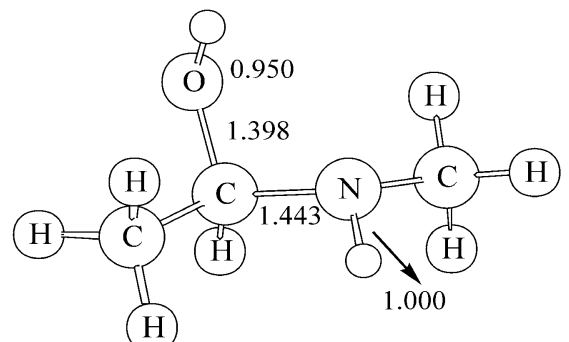

MS2

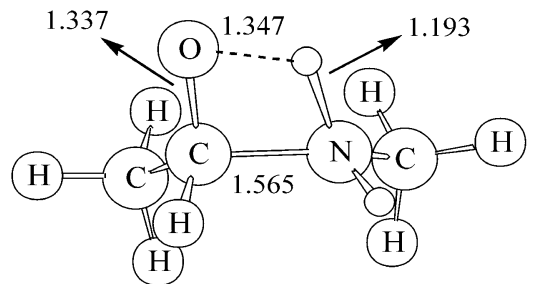

TS1a

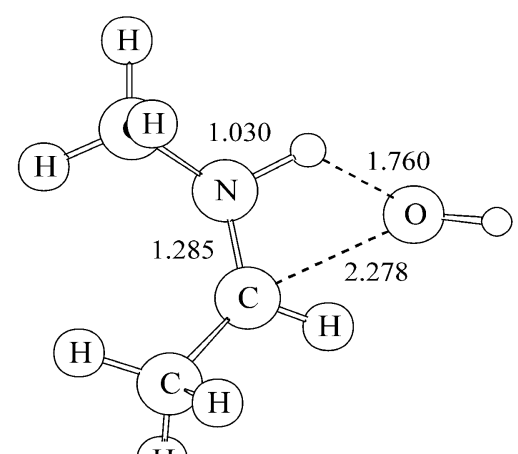

(H)

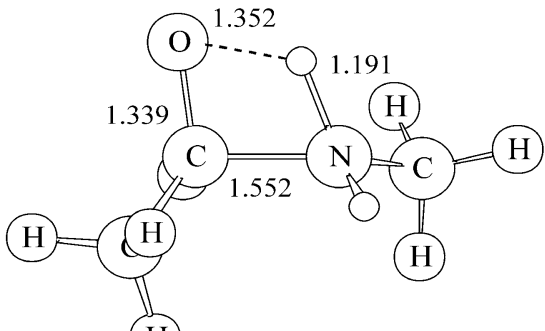

TS1b

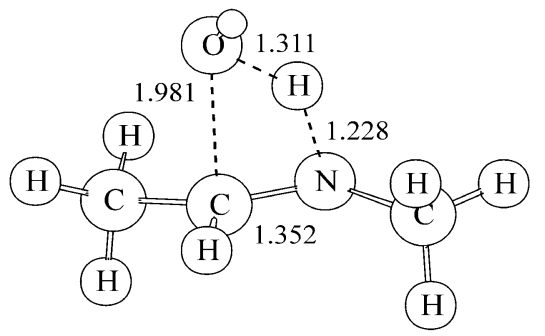

TS2

TS3

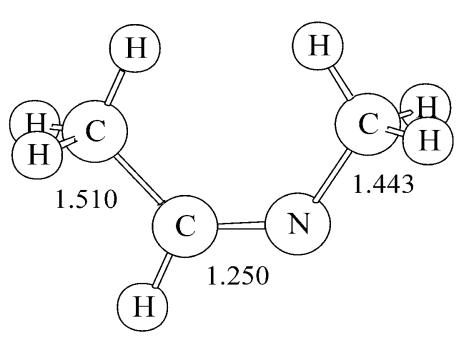

MS3a

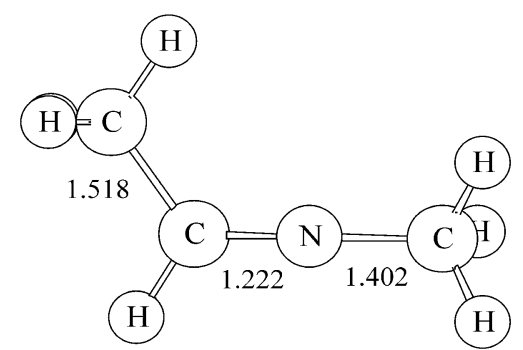

TS4

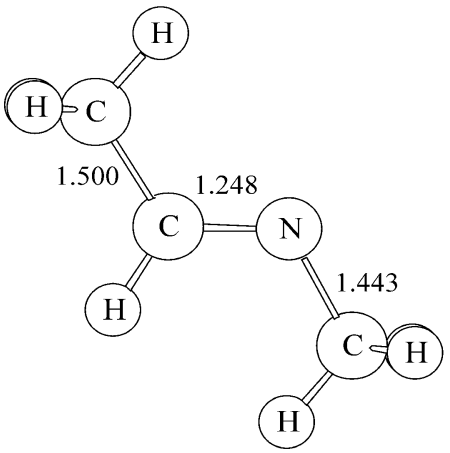

MS3b

Figure 1. Minima (MS) and transition state structures (TS) located on the potential energy surface for the $\mathrm{CH}_{3} \mathrm{NH}_{2}+\mathrm{CH}_{3} \mathrm{CHO}$ reaction. TS1 corresponds to the transition state for step 1 (Scheme 1), TS2 corresponds to the transition state for step 2, and so on. 
7.31 signal to the $E$-isomer, and the $\delta 7.19$ signal to the Z-isomer.

The structures of minima and transition states for the present system are in Fig. 1 and a diagram of the potential energy surface is in Fig. 2. We have located two transition states (TS1a and TS1b) for the first step of methylamine addition to acetaldehyde. In accordance with Yamataka et $a l .{ }^{25}$ study for other amine-aldehyde pairs, no zwitterion intermediate was located on the potential energy surface. The bimolecular process occurs by attack of the nitrogen on the carbonylic carbon and concerted transfer of proton to oxygen, forming the aminoalcohol intermediate (MS2). These transition states have an activation free energy of $35.8 \mathrm{kcal} / \mathrm{mol}$ and $35.0 \mathrm{kcal} / \mathrm{mol}$, respectively, and the $\Delta \mathrm{G}^{*}$ for the formation of the aminoalcohol is $-0.6 \mathrm{kcal} / \mathrm{mol}$. The following step is the elimination of water by an unimolecular process. Depending on the aminoalcohol conformation, either $Z$ - or $E$-isomer can be formed through transition

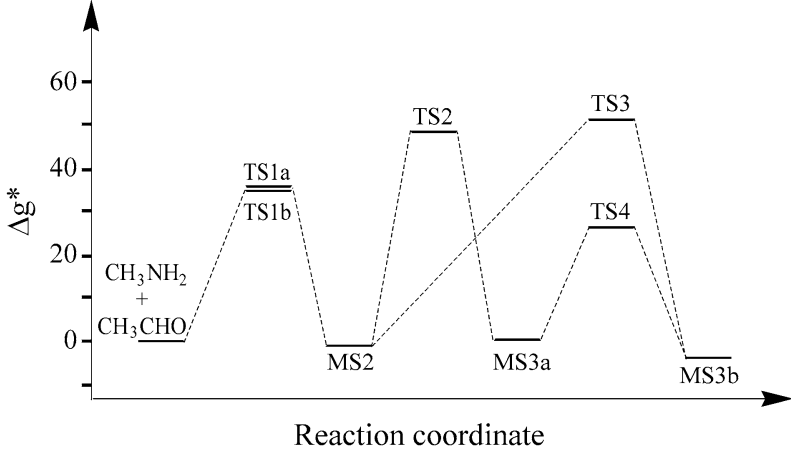

Figure 2. Potential energy surface profile for the $\mathrm{CH}_{3} \mathrm{NH}_{2}+\mathrm{CH}_{3} \mathrm{CHO}$ reaction. Structures of minima and transition states are indicated in accordance with Scheme 1 and Fig. 1. Free energy in $\mathrm{kcal} / \mathrm{mol}$, and standard state of $1 \mathrm{~mol} / \mathrm{L}$.

states TS2 and TS3. These structures present a considerable heterolytic $\mathrm{C}-\mathrm{O}$ bond cleavage, and the forming hydroxyl anion captures the proton bonded to nitrogen to form the

Table 2. Energy barriers, activation thermodynamic properties and rate constants for methylamine addition to acetaldehyde determined by $a b$ initio calculations ${ }^{\mathrm{a}}$.

\begin{tabular}{|c|c|c|c|c|c|}
\hline & $1 \mathrm{a}$ & $1 b$ & 2 & 3 & 4 \\
\hline \multicolumn{6}{|c|}{$6-31 G(d)$} \\
\hline $\mathrm{HF}$ & 47.5 & 45.8 & 73.0 & 77.2 & 27.7 \\
\hline$\Delta \mathrm{ZPE}^{\mathrm{b}}$ & 0.9 & 0.9 & -3.2 & -5.4 & -1.3 \\
\hline \multicolumn{6}{|c|}{$6-31+G(d)$} \\
\hline $\mathrm{HF}$ & 47.1 & 45.4 & 61.9 & 75.1 & 27.3 \\
\hline MP2 & 27.0 & 25.6 & 51.7 & 59.6 & 28.4 \\
\hline \multicolumn{6}{|c|}{$6-311+G(2 d, p)$} \\
\hline MP2 & 25.8 & 24.9 & 52.6 & 57.2 & 28.1 \\
\hline$\Delta \mathrm{E}^{\mathrm{c}}$ & 26.7 & 25.8 & 49.4 & 51.8 & 26.8 \\
\hline \multicolumn{6}{|c|}{ Activation properties ${ }^{\mathrm{d}}$} \\
\hline$\Delta \mathrm{H}^{\mathrm{o}}$ & 25.5 & 24.5 & 50.0 & 52.2 & 26.7 \\
\hline$-\mathrm{T} \Delta \mathrm{S}^{\mathrm{o}}$ & 12.2 & 12.4 & -1.6 & -1.0 & 0.3 \\
\hline$\Delta \mathrm{G}^{\mathrm{o}}$ & 37.7 & 36.9 & 48.4 & 51.2 & 27.0 \\
\hline$\Delta \mathrm{H}^{*}$ & 26.1 & 25.1 & 50.0 & 51.8 & 26.7 \\
\hline$-\mathrm{T} \Delta \mathrm{S}^{*}$ & 9.7 & 9.9 & -1.6 & -1.0 & 0.3 \\
\hline$\Delta \mathrm{G}^{*}$ & 35.8 & 35.0 & 48.4 & 51.2 & 27.0 \\
\hline \multicolumn{6}{|c|}{ Arrhenius parameters and rate constants } \\
\hline $\mathrm{E}_{\mathrm{a}}$ & 26.7 & 25.7 & 50.6 & 52.4 & 27.3 \\
\hline A & $1.3 \times 10^{6}$ & $9.3 \times 10^{5}$ & $2.5 \times 10^{14}$ & $9.1 \times 10^{13}$ & $1.0 \times 10^{13}$ \\
\hline $\mathrm{k}(\mathrm{T})^{\mathrm{e}}$ & $3.6 \times 10^{-14}$ & $1.4 \times 10^{-13}$ & $2.0 \times 10^{-23}$ & $3.6 \times 10^{-25}$ & $1.0 \times 10^{-7}$ \\
\hline
\end{tabular}

a - The numbering corresponds to the transition states in figure 1 and steps in Scheme 1. Energies are in $\mathrm{kcal} / \mathrm{mol} . \mathrm{T}=298.15 \mathrm{~K}$. The Symbols ${ }^{\circ}$ and $*$ correspond to standard state of $1 \mathrm{~atm}$ of pressure and $1 \mathrm{~mol} / \mathrm{L}$ of concentration.

b - Zero point vibrational energy contribution. Frequencies scaled by 0.90 .

c - MP2/6-311+G(2d, p) energy $+\Delta \mathrm{ZPE}$.

$\mathrm{d}$ - The two enantiomers of the aminoalcohol and of the TS1a and TS1b transition states were considered in the calculation of the activation properties. e - Rate constant at $298.15 \mathrm{~K}$ calculated by transition state theory. Units of L, mol and s. 
water molecule. The free energy barriers are $48.4 \mathrm{kcal} / \mathrm{mol}$ and $51.2 \mathrm{kcal} / \mathrm{mol}$, respectively. In relation to aminoalcohol, the $Z$ isomer is $0.5 \mathrm{kcal} / \mathrm{mol}$ less stable, and the $\mathrm{E}$ isomer is $2.8 \mathrm{kcal} / \mathrm{mol}$ lower in free energy. In these calculations, the existence of two enantiomers of the aminoalcohol was taken into account. Also, four other conformations were found for the aminoalcohol, but we have reported only the most stable one, because these conformers can interconvert easily. Thus, they will not be kinetically significant.

Another possible step is the isomerization from the $Z$ form to the $E$ - form by the transition state TS4. This motion corresponds to inversion on the $\mathrm{sp}^{2}$ nitrogen, where the $\mathrm{C}-\mathrm{N}-\mathrm{C}$ atoms are almost collinear. The activation free energy predicted at $298.15 \mathrm{~K}$ is $27.0 \mathrm{kcal} / \mathrm{mol}$.

\section{Discussion}

Considering the competitive steps 2 and 3, the ab initio results suggest that the $Z$-isomer is formed faster than the $E$-isomer, so that under kinetic control, it will be the dominant product. The ${ }^{1} \mathrm{H}-\mathrm{NMR}$ measurements confirm this prediction, with the proportion of products of $63 \%$ of $Z$ and $37 \%$ of $E$-isomers. The thermodynamic data obtained from the calculations indicate that the equilibrium is shifted to the $E$-isomer product, with an overall $\Delta \mathrm{G}^{*}$ of -3.4 $\mathrm{kcal} / \mathrm{mol}$, and it is more stable than the $Z$ isomer by 4.3 $\mathrm{kcal} / \mathrm{mol}$ in $\Delta \mathrm{H}^{*}$ terms, in excellent agreement with the Wiberg $^{31}$ value of $4.4 \mathrm{kcal} / \mathrm{mol}$. So, at thermodynamic equilibrium, only the $E$-isomer will be observed. This result only permits us to infer that the experimentally conducted reaction has not attained thermodynamic equilibrium. However, if we make the assumption that the system is in a quasi-equilibrium state with relation to $Z$-isomer formation, and the water molecules formed remain in pentane solution, we can calculate the $\Delta \mathrm{G}^{*}$ for $Z$-isomer formation from aldehyde and amine as $1.5 \mathrm{kcal} / \mathrm{mol}$ at $230 \mathrm{~K}$, in reasonable agreement with the theoretical value of -0.1 $\mathrm{kcal} / \mathrm{mol}$ at this temperature. The small difference may be due to the quality of the ab initio calculations, the assumption that water molecules remain in pentane solution, and more probably the quasi-equilibrium assumption. Indeed, progression of the reaction would lead to a smaller experimental $\Delta \mathrm{G}^{*}$.

The qualitative analysis of kinetic parameters is in agreement with experimental observations i.e. the $Z$-isomer is the kinetically dominant product. However, the obtained barriers in all steps are very high. In order to have a quantitative comparison between theory and experiment let us make a rough estimate of the experimental free energy for the first step, the formation of the aminoalcohol. If the first step is bimolecular and rate determining for the reaction, and after one hour $20 \%$ of the reactants at $1 \mathrm{~mol} / \mathrm{L}$ have reacted, then we can estimate an activation free energy of $18 \mathrm{kcal} / \mathrm{mol}$ at $230 \mathrm{~K}$, against $33 \mathrm{kcal} / \mathrm{mol}$ obtained by $a b$ initio calculations. The difference of $15 \mathrm{kcal} / \mathrm{mol}$ is very large, and it can not be attributed to the imprecision of the level of theory used. If we observe the barriers for water elimination (steps 2 and 3), they are about $50 \mathrm{kcal} / \mathrm{mol}$. The implication of these results is clear. The first step does not occur via a bimolecular process, and the water elimination step does not occur by a unimolecular mechanism. Some catalyzed mechanism is acting. In the case of reactions in aqueous solution, water molecules play the dominant role as shown by Willians ${ }^{26}$. In the present case, as the reaction was conducted in an aprotic solvent, others species could act as a catalyst, as the proper amine, the aminoalcohol intermediate and the water product. A definitive answer will require more investigation.

The unimolecular isomerization from the $Z$ - to the $E$ isomer presents a $\Delta \mathrm{G}^{* \neq}$ of $26.9 \mathrm{kcal} / \mathrm{mol}$ at $230 \mathrm{~K}$. The resulting rate constant is $1.3 \times 10^{-13} \mathrm{~s}^{-1}$, and this very low value indicates that the $Z$-isomer is kinetically stable at this temperature. So, this pathway can not lead to the $E$-isomer. At room temperature, we obtained $\Delta \mathrm{G}^{* \neq}=27.0 \mathrm{kcal} / \mathrm{mol}$, in excellent agreement with $27.1 \mathrm{kcal} / \mathrm{mol}$ found for $\mathrm{N}$ methyl-1-(1-naphthyl)-ethylimine ${ }^{27}$, which also presents motion of the methyl group bonded to nitrogen. The lifetime to convert the $Z$-isomer to $E$ - isomer, through TS4, is about four months. Thus, the theoretical calculations predict that the $Z$-isomer can be obtained and conserved without isomerization to the $E$-form, since catalytic species are not present and the temperature is kept low.

\section{Conclusion}

The present theoretical and experimental results show that it is possible to obtain the less stable $Z$-isomer under kinetic control as the dominant product. The reaction should be conducted in an aprotic solvent and at low temperature. A drying agent should be used in order to shift the equilibrium toward products.

Analysis of the reaction mechanism shows that in an aprotic and low polarity solvent, the addition step can not be a bimolecular process and neither can the elimination step be unimolecular. A catalyzed mechanism is actuating, and further study is necessary in order to discover the actual reaction pathway.

\section{Acknowledgments}

The authors would like to thank the the Conselho Nacional de Desenvolvimento Científico e Tecnológico (CNPq), the Fundação Coordenação de Aperfeiçoamento de Pessoal de Nível Superior (CAPES) and the Fundação de Amparo a Pesquisa no Estado de Minas Gerais (FAPEMIG) for the support received. We also thank the Centro Nacional de Processamento de Alto Desempenho de Minas Gerais e Região Centro-Oeste (CENAPAD$\mathrm{MG} / \mathrm{CO}$ ) for the computational resources. Antônio F. de C. 
Alcântara would like to thank the Chemistry Department of UFMG.

\section{References}

1. (a) Knapp, S.; Hale, J.J.; Bastos, M.; Gibson, F.S. Tetrahedron Lett. 1990, 31, 2109. (b) Larkin, D.R. J. Org. Chem. 1990, 55, 1563. (c) Mukerjee, A.K.; Singh, A.K. Tetrahedron 1978, 34, 1731. (d) Deshong, P.; Leginus, J.M. J. Org. Chem. 1984, 49, 3421. (e) Shahak, I.; Itah, Y.; Blum, J. Tetrahedron Lett. 1976, 44, 4006. (f) Davis, F.A.; Towson, J.C.; Vashi, D.B.; Thimmareddy, R.; MacCauley, J.P.; Harakal, M.E.; Gosciniak, D.J. J. Org. Chem. 1990, 55, 1254. (g) Zhao, G.; Xue, F.; Zang, Z.-Y.; Mak, T.C.W. Organometallics 1997, 16, 4023.

2. Nielsen, A.T.; Moore, D.W.; Ogan, M.C.; Atkins, R.L. J. Org. Chem. 1979, 44, 1678.

3. (a) Balvenga, J.; Joglar, J.; Ganzales, F.J.; Gotor, V.; Fustero, S. J. Org. Chem. 1988, 53, 5960. (b) Bowman, W.R.; Stephenson, P.T.; Young, A.R. Tetrahedron Lett 1995, 36, 5623.

4.Zombeck, A.; Hamilton, D.E.; Drago, R.S. J. Am. Chem. Soc. 1987, 109, 374.

5. (a) Naid, T.; Kitahara, T.; Kaneda, M.; Nakamura, S. J. Antibiotics 1987, 40, 157. (b) Tepaske, M.R.; Gloer, J.B.; Wicklow, D.T.; Dowd, P.F. J. Org. Chem. 1989, $54,4743$.

6. Szarvas, E. J. Med. Chem. 1973, 16, 281.

7. Druey, J.; Marxer, A. J. Med. Chem. 1959, 1, 1.

8. Schaefer, F.C.; Geoghegan, J.T.; Kaiser, D.W. J. Am. Chem. Soc. 1955, 77, 5918.

9. Bachi, M.D., Sasson, S.; Vaya, J. J. Chem. Soc., Perkin Trans. 1 1980, 2228.

10. Firestone, R.A.; Maliejewicz, N.S.; Christensen, B.G. J. Org. Chem. 1974, 39, 3384.

11. Kamiya, T.; Oku, T.; Nakaguchi, O.; Takeno, H.; Hashimoto, M. Tetrahedron Lett. 1978, 5119.

12. (a) Tashima, T.; Imai, M. J. Org. Chem. 1991, 56, 694. (b) Keeffe, J.R.; Kresge, A.J.; Shepp, N.P.; J. Am. Chem. Soc. 1988, 110, 1993. (c) Brunner, H.; Deml, I.; Dirnberger, W.; Nuber, B.; Reisser, W.; Eur. J. Inorg. Chem. 1998, 43.

13. (a) Patai, S. (ed.) "The Chemistry of the Carbon-Nitrogen Double Bond". John Wiley and Sons, London, 1970. (b) Borton, D.; Ollis, D. "Comprehensive Organic Chemistry - The Synthesis and Reactions of Organic Compounds". Pergamon Press, Oxford, 1979. (c) Dykes, S.F. "The Chemistry of Enamines". Cambridge University Press, London, 1973. (d) Jencks, W. Progr. Phys. Org. Chem. 1964, 2, 63. (e) Hattori, K.; Yamamoto, H. Tetrahedron 1993, 49, 1749. (f) Leardini, R.; Nanni, D.; Santori, M.; Zanardi, G. Tetrahedron 1992, 48, 3961. (g) Musicki, B. J. Org. Chem. 1990, 55, 910. (h) Nielson, A.T.; Nissan, R.A.;
Vanderah, D.J.; Coon, C.L.; Gilardi, R.D.; George, C.F.; Flippen-Anderson, J. J. Org. Chem. 1990, 55, 1459. (i) Nielsen, A.T.; Atkins, R.L.; Moore, D.W.; Scott, R.; Mallory, D.; LaBerger, J.M. J. Org. Chem. 1973, 38, 3288. (j) Rossi, M.H.; Atachissini, A.S.; Amaral, L. J. Org. Chem. 1990, 55, 1300. (k) Forlani, L.; Marianucci, E.; Todesco, P.E. J. Chem. Res. (S) 1984, 126. (l) Alzuet, G.; Casella, L.; Villa, M.L.; Carugo, O.; Gullotti, M. J. Chem. Soc., Dalton Trans. 1997, 4789.

14. (a) Costero, A.M.; Rodrigues, S. Tetrahedron Lett. 1992, 33, 623. (b) Yuliang, W.; Aiqiao, M.; Yaozhong, J. Synth. Commun. 1992, 22, 265. (c) Sollandi'e-Cavallo, A.; Bencheqroun, M.; Bonne, F. Synth. Commun. 1993, 23, 1683. (d) Levin, M. J. Org. Chem. 1991, 56, 5707. (e) Suh, J.; Min, D. W. J. Org. Chem. 1991, 56, 5710. (f) Texier-Boullet, F. Synthesis, commun. 1985, 679. (g) Campbell, K.N.; Sommers, A.H.; Campbell, B.K. J. Am. Chem. Soc. 1944, 66,82 .

15. (a) Grigg, R.; Montgomery, J.; Somasunderam, A. Tetrahedron 1992, 48, 10431. (b) de Kimpe, N.; Verhe, R.; de Buyck, L.; Schamp, N. J. Royal Nettherlands Chem. Soc. 1977, 96, 242. (c) Poirier, R.A.; Yu, D.; Surjan, P.R. Canad. J. Chem. 1991, 69, 1589. (d) Arjona, O.; Pérez-Ossorio, R.; Pérez-Rubalcaba, A.; Plumet, J.; Santesmases, M.J. J. Org. Chem. 1984, 49, 2624. (e) Gilson, H.S.R.; Honig, B.H.; Croteau, A.; Zarrilli, G.; Nakanishi, K. Biophys. J. 1988, 53, 261. (f) Fustero, S.; Díaz, M.D.; Carlón, R.P. Tetrahedron Lett. 1993, 34, 725. (g) Bruice, P.Y. J. Am. Chem. Soc. 1989, 111, 962. (h) Bureau, R.; Joucla, M. Tetrahedron Lett. 1990, 31, 6017. (i) Clark, A.A.; Parker, D.C. J. Am. Chem. Soc. 1971, 93, 7257. (j) Teysseyre, J.; Arriau, J.; Dargelos, A.; Elguero, J.; Katritzky, A.R. Bull. Soc. Chim. Belges 1976, 85, 39. (k) Ahlbrecht, H.; Hanisch, H.; Funk, W.; Kalas, R.D. Tetrahedron 1972, 28, 5481. (1) Cave, C.; Deslmaele, D.; d'Angelo, J.; Riche, C.; Chiaroni, A. J. Org. Chem. 1996, 61, 4361.

16. Smith, P.A.S.; Dang, C.V. J. Org. Chem. 1976, 41, 2013.

17. (a) Jennings, W.B.; Lovely, C.J. Tetrahedron Lett. 1988, 29, 3725. (b) Sevilla, J.M.; Blazquez, M.; Dominguez, M.; Garcia-Blanco, F. J. Chem. Soc., Perkin Trans. 2 1992, 921. (c) Nagata, W.; Hayase, Y. Tetrahedron Lett. 1968, 4359. (d) Chiang, Y.; Kresge, A.J.; Walsh, P.A. J. Org. Chem. 1990, 55, 1309. (e) Onys'ko, P.P.; Kim, T.V.; Kiseleva, E.I.; Sinitsa, A.D. Tetrahedron Lett. 1992, 33, 691. (f) Csaszar, J. Acta Phys. Chem., Szeged 1981, 25, 47. (g) Geirsson, J.K.F.; Johannesdottir, J.F. J. Org. Chem. 1996, 61, 7320.

18. 
(a) Wasserman, H.H.; van Buzer, J.H.; Vu, C.B. Tetrahedron Lett. 1990, 31, 1609. (b) Campbell, K.N. J. Am. Chem. Soc. 1944, 66, 82. (c) Weingarten, H.; Chupp, J.P.; White, W.A. J. Org. Chem. 1967, 32, 3246. (d) Kallen, R.G.; Jencks, W.P. J. Biol. Chem. 1966, 241, 5864. (e) Tiollais, R. Bull. Soc. Chim. France 1947, 14, 716. (f) Nielsen, A.T.; Atkins, R.L.; DiPol, J.; Moore, D.W. J. Org. Chem. 1974, 39, 1349. (g) Zwierzak, A.; Napieraj, A. Tetrahedron 1996, 52, 8789. (h) Shiraishi, H.; Kawasaki, Y.; Sakaguchi, S.; Nishiyama, Y.; Ishii, Y. Tetrahedron Lett. 1996, 37, 7291.

19. (a) Mladenova, M.; Ballassoued, M. Synth. Commun. 1993, 23, 725. (b) Ramasseul, R.; Tavares, M.; Marchon, J.-C. J. Chem.Res (S) 1992, 104. (c) Larkin, D.R. J. Org. Chem. 1990, 55, 1563. (d) Kallen, R.G.; Jencks, W.P. J. Biol. Chem. 1966, 241, 5864. (e) Varma, R.S.; Dahiya, R.; S. Kumar Tetrahedron Lett. 1997, 38, 2039.

20. Sayer, J.M.; Peskin, M.; Jencks, W.P. J. Am. Chem. Soc. 1973, 95, 4277.

21. Rosenberg, S.; Silver, S.M.; Sayer, J.M.; Jencks, W.P. J. Am. Chem. Soc. 1974, 96, 7986.

22. Sayer, J.M.; Pinsky, B.; Schonbrunn, A.; Washtien, W. J. Am. Chem. Soc. 1974, 96, 7998.

23. Kayser, R.H.; Pollak, R.M. J. Am. Chem. Soc. 1977, 99, 3379.

24. Brighente, I.M.C.; Yunes, R.A. J. Braz. Chem. Soc. 1997, 8, 549.

25. Yamataka, H.; Nagase, S.; Ando, T.; Hanafusa, T. J. Am. Chem. Soc. 1986, 108, 601.

26. Williams, I.H. J. Am. Chem. Soc. 1987, 109, 6299.

27. Jennings, W.B.; Boyd, D.R. J. Am. Chem. Soc. 1972, $94,7187$.
28. Bjorgo, J.; Boyd, D.R.; Watson, C.G.; Jennings, W.B. J. Chem. Soc., Perkin Trans. II 1974, 757.

29. Pople, J.A.; Raghavachari, K.; Frisch, M.J.; Binkley, J.S.; Schleyer, P.V.R. J. Am. Chem. Soc. 1983, 105, 6389.

30. Boyd, D.R.; Jennings, W.B.; Waring L.C. J. Org. Chem. 1986, 51, 992.

31. Wiberg, K.; Nakaji, D.Y.; Morgan, K.M. J. Am. Chem. Soc. 1993, 115, 3527.

32. Lammertsma, L.; Prasad, B.V. J. Am. Chem. Soc. 1994, 116, 642.

33. Lin, J.F.; Wu, C.C.; Lien, M.H. J. Phys. Chem. 1995, 99, 16903.

34. Guerra, A.; Lunazzi, L. J. Org. Chem. 1995, 60, 7959.

35. Hill, T. L. An Introduction to Statistical Thermodynamics, Dover publications, 1986.

36. Steinfeld, J.I.; Francisco, J.S.; Hase, W.L. Chemical Kinetics and Dynamics, Prentice Hall, New Jersey 1989.

37. Pliego, J.R., Jr.; De Almeida, W.B. Phys. Chem. Chem. Phys. 1999, 1, 1031.

38. Gaussian 94, Revision D.2, Frisch, M.J.; Trucks, G.W.; Schlegel, H.B.; Gill, P.M.W.; Johnson, B.G.; Robb, M.A.; Cheeseman, J.R.; Keith, T.; Petersson, G.A.; Montgomery, J.A.; Raghavachari, K.; Al-Laham, M.A.; Zakrzewski, V.G.; Ortiz, J.V.; Foresman, J.B.; Cioslowski, J.; Stefanov, B.B.; Nanayakkara, A.; Challacombe, M.; Peng, C.Y.; Ayala, P.Y.; Chen, W.; Wong, M.W.; Andres, J.L.; Replogle, E.S.; Gomperts, R.; Martin, R.L.; Fox, D.J.; Binkley, J.S.; Defrees, D.J.; Baker, J.; Stewart, J.P.; Head-Gordon, M.; Gonzalez, C.; Pople, J.A. Gaussian, Inc., Pittsburgh PA, 1995. 